\title{
A NON-STATIONARY MODEL OF THE INCOMPRESSIBLE VISCOELASTIC KELVIN-VOIGT FLUID OF NON-ZERO ORDER IN THE MAGNETIC FIELD OF THE EARTH
}

\author{
A.O. Kondyukov ${ }^{1}$, T.G. Sukacheva ${ }^{1,2}$ \\ ${ }^{1}$ Novgorod State University, Velikiy Novgorod, Russian Federation \\ ${ }^{2}$ South Ural State University, Chelyabinsk, Russian Federation \\ E-mails: k.a.o_leksey999@mail.ru, tamara.sukacheva@novsu.ru
}

\begin{abstract}
We investigate the Cauchy-Dirichlet problem for a system of Oskolkov equations of nonzero order. The considered mathematical model describes the flow of an incompressible viscoelastic Kelvin-Voigt fluid in the magnetic field of the Earth. The model takes into account that the fluid is subject to various external influences, which depend on both the coordinate of the point in space and the time. The first part of the paper presents the known results obtained by the authors earlier and based on the theory of solvability of the Cauchy problem for semilinear nonautonomous Sobolev type equations. In the second part, we reduce the considered mathematical model to an abstract Cauchy problem. In the third part, we prove the main result that is the theorem on the existence and uniqueness of the solution. Also, we establish the conditions for the existence of quasi-stationary semitrajectories, and describe the extended phase space of the model under study. In this paper, we summarize our results for the Oskolkov system that simulates the motion of a viscoelastic incompressible Kelvin-Voigt fluid of zero order in the magnetic field of the Earth.
\end{abstract}

Keywords: magnetohydrodynamics; Sobolev type equations; extended phase space; incompressible viscoelastic fluid.

\section{Introduction}

The Oskolkov's system of equations

$$
\begin{aligned}
& \left(1-\varkappa \nabla^{2}\right) v_{t}=\nu \nabla^{2} v-(v \cdot \nabla) v+\sum_{l=1}^{K} \beta_{l} \nabla^{2} w_{l}-\frac{1}{\rho} \nabla p-2 \Omega \times v+\frac{1}{\rho \mu}(\nabla \times b) \times b+f^{1}, \\
& \nabla \cdot v=0, \quad \nabla \cdot b=0, \quad b_{t}=\delta \nabla^{2} b+\nabla \times(v \times b)+f^{2}, \\
& \frac{\partial w_{l}}{\partial t}=v+\alpha_{l} w_{l}, \quad \alpha_{l} \in \mathbb{R}_{-}, \quad \beta_{l} \in \mathbb{R}_{+}, \quad l=\overline{1, K},
\end{aligned}
$$

simulates the flow of an incompressible viscoelastic Kelvin-Voigt fluid [1] of nonzero order $K$ in the magnetic field of the Earth. Here the vector functions $v=$ $\left(v_{1}(x, t), v_{2}(x, t), \ldots, v_{n}(x, t)\right)$ and $b=\left(b_{1}(x, t), b_{2}(x, t), \ldots, b_{n}(x, t)\right)$ characterize fluid velocity and magnetic induction, respectively, $p=p(x, t)$ is the pressure, $\varkappa$ is the coefficient of elasticity, $\nu$ is the coefficient of viscosity, $\Omega$ is the corner velocity, $\delta$ is the magnetic viscosity, $\mu$ is the magnetic permeability, $\rho$ is the density, and the parameters $\beta_{l}, \quad l=\overline{1, K}$ determine the time of pressure retardation (delay). The absolute terms $f^{1}=\left(f_{1}^{1}, \ldots, f_{n}^{1}\right), f_{i}^{1}=f_{i}^{1}(x, t), f^{2}=f^{2}(x, t)$ correspond to external influences on the fluid.

Consider the first initial boundary value problem for system (1):

$$
\begin{aligned}
& v(x, 0)=v_{0}(x), \quad b(x, 0)=b_{0}(x), \quad w_{l}(x, 0)=w_{l 0}(x) \quad x \in D, \\
& v(x, t)=0, \quad b(x, t)=0, \quad w_{l}(x, t)=0 \quad(x, t) \in \partial D \times \mathbb{R}_{+}, \quad l=\overline{1, K}
\end{aligned}
$$


under assumption that $\mu=1$ and $\rho=1$. Here $D \subset \mathbb{R}^{n}$ is a bounded domain with the boundary $\partial D$ of the class $C^{\infty}$.

Problems that are similar to problem (1), (2) take place, for example, in mathematical modelling in geophysical sciences [2].

Note that degenerate models of magnetohydrodynamics were previously studied by the authors in the papers [3-6]. A distinctive feature of the present paper is the presence of the vector-functions $f^{1}=\left(f_{1}^{1}, \ldots, f_{n}^{1}\right), f_{i}^{1}=f_{i}^{1}(x, t), f^{2}=f^{2}(x, t)$ in the right hand side of equation (1). The paper [7] considers the model of magnetohydrodynamics, which takes into account various external influences for $K=0$. The case of $K>0$ is investigated for the first time.

Problem (1), (2) is investigated in the framework of the theory of semilinear Sobolev type equations $[8,9]$. The main tool of the study is the notion of a relative $p$-sectorial operator and a resolving degenerate semigroup of operators generated by this operator $[10,11]$. We prove the theorem on the existence and uniqueness of the solution to this problem, and describe the extended phase space of the problem.

The article consists of three sections. Section 1 gives the known necessary results of the theory of semi-linear Sobolev type equations [10,12]. Section 2 reduces problem (1), (2) to the Cauchy problem for the semi-linear Sobolev type equation. Section 3 presents the theorem on the existence and uniqueness of the solution to the considered problem, shows that the solution is a quasi-stationary trajectory, and describes the extended phase space of the problem.

\section{Semi-Linear Non-Stationary Sobolev Type Equations}

Let $\mathcal{U}$ and $\mathcal{F}$ be Banach spaces, the operator $L \in \mathcal{L}(\mathcal{U} ; \mathcal{F})$, i.e. $L$ is linear and continuous, the operator $M$ : $\operatorname{dom} M \rightarrow \mathcal{F}$ be linear, closed and densely defined in $\mathcal{U}$, i.e. $M \in \mathcal{C l}(\mathcal{U} ; \mathcal{F})$. Denote $\mathcal{U}_{M}=\left\{u \in \operatorname{dom} M:\|u\|=\|M u\|_{\mathcal{F}}+\|u\|_{\mathcal{U}}\right\}$. Let the operator $F \in C^{\infty}\left(\mathcal{U}_{M} ; \mathcal{F}\right)$. We suppose that the operator $F \in \mathcal{C}^{\infty}\left(\mathcal{U}_{M} ; \mathcal{F}\right)$, and the function $f \in \mathcal{C}^{\infty}\left(\overline{\mathbb{R}}_{+} ; \mathcal{F}\right)$.

Consider the Cauchy problem

$$
u(0)=u_{0}
$$

for the semi-linear non-stationary Sobolev type equation

$$
L \dot{u}=M u+F(u)+f(t) .
$$

By a local solution (hereinafter, solution) to problem (3), (4) we mean the vector function $u \in \mathcal{C}^{\infty}\left((0, T) ; \mathcal{U}_{M}\right)$ that satisfies equation (4) and such that $u(t) \rightarrow u_{0}$ for $t \rightarrow 0+$.

Let the operator $M$ be strongly $(L, p)$-sectorial [12]. It is well known that, under this condition, problem (3), (4) can have several solutions [13]. Therefore, we are interested in only such solutions to problem (3), (4) that are quasi-stationary semitrajectories.

Definition 1. Suppose that the space $\mathcal{U}$ splits into the direct sum $\mathcal{U}=\mathcal{U}_{0} \oplus \mathcal{U}_{1}$ such that ker $L \subset \mathcal{U}_{0}$. A solution $u=v+w$ to equation (4), where $v(t) \in \mathcal{U}_{0}$ and $w(t) \in \mathcal{U}_{1}$ for all $t \in(0, T)$, is called a quasi-stationary semitrajectory, if $L \dot{v} \equiv 0$.

Also, it is known [12] that problem (3), (4) can has no solutions for some $u_{0} \in \mathcal{U}_{M}$. Therefore, we introduce another definition.

Definition 2. The set $\mathcal{B}^{t} \subset \mathcal{U}_{M} \times \overline{\mathbb{R}}_{+}$is called the extended phase space of equation (4), if for any point $u_{0} \in \mathcal{U}_{M}$ such that $\left(u_{0}, 0\right) \in \mathcal{B}^{0}$ there exists a unique solution to problem $(3),(4)$, and $(u(t), t) \in \mathcal{B}^{t}$. 
We consider problem (3), (4) under the condition that the operator $M$ is strongly $(L, p)$-sectorial [12]. In this case, the problem can have no solution for some $u_{0} \in \mathcal{U}_{M}$, and even if there exists a solution for all $u_{0} \in \mathcal{U}_{M}$, then the solution can be non-unique.

It is well known that if the operator $M$ is strongly $(L, p)$-sectorial, then $\mathcal{U}=\mathcal{U}^{0} \oplus \mathcal{U}^{1}$, $\mathcal{F}=\mathcal{F}^{0} \oplus \mathcal{F}^{1}$, where $\mathcal{U}^{0}=\left\{\varphi \in \mathcal{U}: U^{t} \varphi=0 \quad \exists t \in \mathbb{R}_{+}\right\}, \mathcal{F}^{0}=\left\{\psi \in \mathcal{F}: F^{t} \psi=0 \quad \exists t \in \mathbb{R}_{+}\right\}$ are the kernels, and $\mathcal{U}^{1}=\left\{u \in \mathcal{U}: \lim _{t \rightarrow 0+} U^{t} u=u\right\}, \mathcal{F}^{1}=\left\{f \in \mathcal{F}: \lim _{t \rightarrow 0+} F^{t} f=f\right\}$ are the images of the analytic solving semigroups

$$
U^{t}=\frac{1}{2 \pi i} \int_{\Gamma} R_{\mu}^{L}(M) e^{\mu t} d \mu, F^{t}=\frac{1}{2 \pi i} \int_{\Gamma} L_{\mu}^{L}(M) e^{\mu t} d \mu
$$

of the linear homogeneous equation

$$
L \dot{u}=M u,
$$

where $\Gamma \subset S_{\Theta, a}^{L}(M)$ is a contour such that $\arg \mu \rightarrow \pm \Theta$ for $|\mu| \rightarrow+\infty$.

Denote by $L_{k}$ and $M_{k}$ the restrictions of the operators $L$ and $M$ on $\mathcal{U}^{k}\left(\mathcal{U}^{k} \cap\right.$ $\operatorname{dom} M), \quad k=0,1$, respectively. Then $L_{k}: \mathcal{U}^{k} \rightarrow \mathcal{F}^{k}, \quad M_{k}: \mathcal{U}^{k} \cap \operatorname{dom} M \rightarrow \mathcal{F}^{k}, \quad k=$ 0,1 , and the restrictions $M_{0}$ and $L_{1}$ of the operators $M$ and $L$ on the spaces $\mathcal{U}^{0} \cap \operatorname{dom} M$ and $\mathcal{U}^{1}$ are linear continuous operators and have bounded inverse operators.

Therefore, problem (3), (4) is reduced to an equivalent system, which we call the normal form of problem (3), (4):

$$
\begin{array}{cc}
R \dot{u}^{0}=u^{0}+G(u)+g(t), & u^{0}(0)=u_{0}^{0}, \\
\dot{u}^{1}=S u^{1}+H(u)+h(t) & u^{1}(0)=u_{0}^{1},
\end{array}
$$

where $u^{k} \in \mathcal{U}^{k}, \quad k=0,1, u=u^{0}+u^{1}$, the operators $R=M_{0}^{-1} L_{0}, \quad S=L_{1}^{-1} M_{1}, \quad G=$ $M_{0}^{-1}(I-Q) F, \quad H=L_{1}^{-1} Q F, \quad g=M_{0}^{-1}(I-Q) f, \quad h=L_{1}^{-1} Q f$.

Here $Q \in \mathcal{L}(F)(\equiv \mathcal{L}(F ; F))$ is the projector that splits the space $\mathcal{F}$ as required.

Further, we study only the quasi-stationary semitrajectories of equation (4), for which $R \dot{u}^{0} \equiv 0$. To this end, we assume that the operator $R$ is bi-splitting, i.e. the kernel ker $R$ and the image $\operatorname{im} R$ are completed in the space $\mathcal{U}$. Suppose that $\mathcal{U}^{00}=$ ker $R$. Denote by $\mathcal{U}^{01}=\mathcal{U}^{0} \ominus \mathcal{U}^{00}$ a complement of the subspace $\mathcal{U}^{00}$. Then the first equation of normal form (7) is reduced to

where $u=u^{00}+u^{01}+u^{1}$.

$$
R \dot{u}^{01}=u^{00}+u^{01}+G(u)+g(t)
$$

Theorem 1. Let the operator $M$ be strongly $(L, p)$-sectorial, and the operator $R$ be bisplitting. Suppose that there exists the quasi-stationary semitrajectory $u=u(t)$ of equation (4). Then $u=u(t)$ satisfies the following relations:

$$
0=u^{00}+u^{01}+G(u)+g(t), u^{01}=\text { const. }
$$

It is known that if the operator $M$ is strongly $(L, p)$-sectorial, then the operator $S$ is sectorial. Therefore, on $\mathcal{U}^{1}$, the operator $S$ generates an analytic semigroup, which we denote by $\left\{U_{1}^{t}: t \geq 0\right\}$, since the operator $U_{1}^{t}$ is a restriction of the operator $U^{t}$ on $\mathcal{U}^{1}$.

Since $\mathcal{U}=\mathcal{U}^{0} \oplus \mathcal{U}^{1}$, then there exists the projector $P \in \mathcal{L}(\mathcal{U})$ corresponding to this splitting. It is easy to see that $P \in \mathcal{L}\left(\mathcal{U}_{M}\right)$. Then the space $\mathcal{U}_{M}$ splits into the direct sum $\mathcal{U}_{M}=\mathcal{U}_{M}^{0} \oplus \mathcal{U}_{M}^{1}$ such that the embedding $\mathcal{U}_{M}^{k} \subset \mathcal{U}^{k}, \quad k=0,1$, is dense and continuous. Further, denote by $A_{v}^{\prime}$ the Frechet derivative at the point $v \in \mathcal{V}$ of the operator $A$ defined on the Banach space $\mathcal{V}$.

Theorem 2. Let the operator $M$ be strongly $(L, p)$-sectorial, the operator $R$ be bi-splitting, the operator $F \in \mathcal{C}^{\infty}\left(\mathcal{U}_{M} ; \mathcal{F}\right)$, and the vector-function $f \in \mathcal{C}^{\infty}\left(\mathbb{R}_{+} ; \mathcal{F}\right)$. Suppose that the following conditions are fulfilled. 
(i) In the neighborhood $\mathcal{O}_{u_{0}} \subset \mathcal{U}_{M}$ of the point $u_{0}$, the following relation takes place:

$$
0=u_{0}^{01}+\left(I-P_{R}\right)\left(G\left(u^{00}+u_{0}^{01}+u^{1}\right)+g(t)\right) .
$$

(ii) The projector $P_{R} \in \mathcal{L}\left(\mathcal{U}_{M}^{0}\right)$, and the operator $I+P_{R} G_{u_{0}^{0}}^{\prime}: \mathcal{U}_{M}^{00} \rightarrow \mathcal{U}_{M}^{00}$ is the topological linear isomorphism $\left(\mathcal{U}_{M}^{00}=\mathcal{U}_{M} \cap \mathcal{U}^{00}\right)$.

(iii) For the analytic semigroup $\left\{U_{1}^{t}: t \geq 0\right\}$, the following condition is fulfilled:

$$
\int_{0}^{\tau}\left\|U_{1}^{t}\right\|_{\mathcal{L}\left(\mathcal{U}^{1} ; \mathcal{U}_{M}^{1}\right)} d t<\infty \quad \forall \tau \in \mathbb{R}_{+} .
$$

Then there exists the unique solution to problem (3), (4), which is the quasi-stationary semitrajectory.

Remark 1. Condition (11) is not satisfied for ordinary analytic semigroups having the estimate $\left\|U_{1}^{t}\right\|_{\mathcal{L}\left(\mathcal{U}^{1} ; \mathcal{U}_{M}^{1}\right)}<$ const $/ t$. Denote by $\mathcal{U}_{\alpha}^{1}=\left[\mathcal{U}^{1} ; \mathcal{U}_{M}^{1}\right]_{\alpha}, \alpha \in[0,1]$, some interpolation space constructed by the operator $S$. Complete the condition $F \in \mathcal{C}^{\infty}\left(\mathcal{U}_{M}^{1} ; \mathcal{F}\right)$ of Theorem 2 with the condition $H \in \mathcal{C}^{\infty}\left(\mathcal{U}_{M}^{1} ; \mathcal{U}_{\alpha}^{1}\right)$, and replace Condition (11) with

$$
\int_{0}^{\tau}\left\|U_{1}^{t}\right\|_{\mathcal{L}\left(\mathcal{U}^{1} ; \mathcal{U}_{\alpha}^{1}\right)} d t<\infty, \quad \tau \in \mathbb{R}_{+} .
$$

Then the statement of Theorem 2 is the same.

Let $\mathcal{U}_{k}$ and $\mathcal{F}_{k}$ be Banach spaces, the operators $A_{k} \in \mathcal{L}\left(\mathcal{U}_{k}, \mathcal{F}_{k}\right)$, and the operators $B_{k}: \quad \operatorname{dom} B_{k} \rightarrow \mathcal{F}$ be linear and closed with domain of definitions dom $B_{k}$, which are dense in $\mathcal{U}_{k}, \quad k=1,2$. Construct the spaces $\mathcal{U}=\mathcal{U}_{1} \times \mathcal{U}_{2}, \quad \mathcal{F}=\mathcal{F}_{1} \times \mathcal{F}_{2}$ and the operators $L=A_{1} \otimes A_{2}, \quad M=B_{1} \otimes B_{2}$. By the construction, the operator $L \in \mathcal{L}(\mathcal{U} ; \mathcal{F})$, and the operator $M: \operatorname{dom} M \rightarrow \mathcal{F}$ is linear, closed and densely defined, $\operatorname{dom} M=$ $\operatorname{dom} B_{1} \times \operatorname{dom} B_{2}$.

Theorem 3. Let the operators $B_{k}$ be strongly $\left(A_{k}, p_{k}\right)$-sectorial, $k=1,2$, and $p_{1} \geq p_{2}$. Then the operator $M$ is strongly $\left(L, p_{1}\right)$-sectorial.

\section{Reduction to Abstract Cauchy Problem}

In order to reduce problem (1), (2) to problem (3), (4), we transfer from system (1) to the system

$$
\begin{aligned}
& \left(1-\varkappa \nabla^{2}\right) v_{t}=\nu \nabla^{2} v-(v \cdot \nabla) v+\sum_{l=1}^{K} \beta_{l} \nabla^{2} w_{l}-\bar{p}-2 \Omega \times v+(\nabla \times b) \times b+f^{1}, \\
& \nabla(\nabla \cdot v)=0, \quad \nabla(\nabla \cdot b)=0, \quad b_{t}=\delta \nabla^{2} b+\nabla \times(v \times b)+f^{2} . \\
& \frac{\partial w_{l}}{\partial t}=v+\alpha_{l} w_{l}, \quad \alpha_{l} \in \mathbb{R}_{-}, \quad \beta_{l} \in \mathbb{R}_{+}, \quad l=\overline{1, K} .
\end{aligned}
$$

We are interested in solvability of problem (13), (2). Following the paper [12], we introduce the spaces $\mathbf{H}_{\sigma}^{2}, \quad \mathbf{H}_{\pi}^{2}, \quad \mathbf{H}_{\sigma}$, and $\mathbf{H}_{\pi}$. Here $\mathbf{H}_{\sigma}^{2}$ and $\mathbf{H}_{\sigma}$ are subspaces of the solenoid functions in the spaces $\left(W_{2}^{2}(D)\right)^{n} \cap$ $\cap\left(\stackrel{\circ}{W}_{2}^{1}(D)\right)^{n}$ and $\left(L_{2}(D)\right)^{n}$, respectively, and $\mathbf{H}_{\pi}^{2}$ and $\mathbf{H}_{\pi}$ are their orthogonal (in the sense of $\left.\left(L_{2}(D)\right)^{n}\right)$ complements. Denote by $\Sigma$ both the orthoprojector on $\mathbf{H}_{\sigma}$ and its 
restriction on the space $\left(W_{2}^{2}(D)\right)^{n} \cap\left(\stackrel{\circ}{W}_{2}^{1}(D)\right)^{n}$. Suppose that $\Pi=I-\Sigma$. The equality $A=\nabla^{2} E_{n}: \mathbf{H}_{\sigma}^{2} \oplus \mathbf{H}_{\pi}^{2} \rightarrow \mathbf{H}_{\sigma} \oplus \mathbf{H}_{\pi}$, where $E_{n}$ is a unit matrix of order $n$, defines a linear continuous matrix operator with discrete finite-multiple spectrum $\sigma(A) \subset \mathbb{R}$ that tends only to $-\infty$. The formula $B_{v}: v \rightarrow \nabla(\nabla \cdot v)\left(B_{b}: b \rightarrow \nabla(\nabla \cdot b)\right)$ gives the linear continuous surjective operator $B_{v}\left(B_{b}\right): \mathbf{H}_{\sigma}^{2} \oplus \mathbf{H}_{\pi}^{2} \rightarrow \mathbf{H}_{\pi}$ with the kernel ker $B_{v}=B_{b}=\mathbf{H}_{\sigma}^{2}$. We use the natural isomorphism of the direct sum and the Cartesian product of Banach spaces in order to introduce the spaces $\mathcal{U}_{10}=\mathbf{H}_{\sigma}^{2} \times \mathbf{H}_{\pi}^{2} \times \mathbf{H}_{p}, \quad \mathcal{F}_{10}=\mathbf{H}_{\sigma} \times \mathbf{H}_{\pi} \times \mathbf{H}_{p}$, where $\mathbf{H}_{p}=\mathbf{H}_{\pi} ; \mathcal{U}_{1 i}=\mathbf{H}^{2} \cap \stackrel{\circ}{\mathbf{H}^{1}}=\mathbf{H}_{\sigma}^{2} \times \mathbf{H}_{\pi}^{2}$, and $\mathcal{F}_{1 i}=\mathbf{L}_{2}=\mathbf{H}_{\sigma} \times \mathbf{H}_{\pi}, i=\overline{1, K}$. Then spaces $\mathcal{U}_{1}=\oplus_{l=0}^{K} \mathcal{U}_{1 l}, \quad \mathcal{F}_{1}=\oplus_{l=0}^{K} \mathcal{F}_{1 l}$.

The operators $A_{1}$ and $B_{1}$ are defined by the formulas $A_{1}=\operatorname{diag}\left[\hat{A}_{1}, E_{k}\right]$, where

$$
\hat{A}_{1}=\left(\begin{array}{cc}
\check{A_{1}} & O \\
O & O
\end{array}\right), \quad \check{A}_{1}=\left(\begin{array}{cc}
\Sigma(I-\lambda A) \Sigma & \Sigma A(I-\lambda A) \Pi \\
\Pi(I-\lambda A) \Sigma & \Pi A(I-\lambda A) \Pi
\end{array}\right)
$$

$B_{1}=\left(B_{1}^{i j}\right)_{i, j=1}^{2}$, where

$$
B_{1}^{11}=\left(\begin{array}{ccc}
\nu \Sigma A & \nu \Sigma A & O \\
\nu \Pi A & \nu \Pi A & -I \\
O & B & O
\end{array}\right), \quad B_{1}^{12}=\left(\begin{array}{ccc}
\beta_{1} \Sigma A & \ldots & \beta_{K} \Sigma A \\
\beta_{1} \Pi A & \ldots & \beta_{K} \Pi A \\
O & \ldots & O
\end{array}\right) .
$$

In the matrix $B_{1}^{11}, B=\nabla(\nabla \cdot v)-\nabla(\nabla \cdot b)=B_{v}-B_{b}$. The matrix $B_{1}^{21}$ contains $K$ rows of the form $(I, I, O), B_{1}^{22}=\operatorname{diag}\left[\alpha_{1}, \ldots, \alpha_{K}\right]$.

Remark 2. Denote by $A_{\sigma}$ the restriction of the operator $\Sigma A$ on $\mathbf{H}_{\sigma}^{2}$. According to the Solonnikov-Vorovich-Yudovich theorem, the spectrum $\sigma\left(A_{\sigma}\right)$ is real, discrete, finitemultiple, and tends only to $-\infty$.

\section{Theorem 4.}

i) The operators $A_{1}, B_{1}$ belong to $\mathcal{L}\left(\mathcal{U}_{1} ; \mathcal{F}_{1}\right)$, and if $\varkappa^{-1} \notin \sigma(A)$, then the operator $A_{1}$ is bi-splitting, $\operatorname{ker} A_{1}=\{0\} \times\{0\} \times \mathbf{H}_{p} \times \underbrace{\{0\} \times \ldots \times\{0\}}_{K}$, im $A_{1}=\mathbf{H}_{\sigma} \times \mathbf{H}_{\pi} \times\{0\} \times \mathcal{F}_{1} \times$ $\mathcal{F}_{2} \times \ldots \times \mathcal{F}_{K}$

ii) If $\lambda^{-1} \notin \sigma(A) \cup \sigma\left(A_{\sigma}\right)$, then the operator $B_{1}$ is $\left(A_{1}, 1\right)$-bounded.

Proof. The statement of the theorem is the direct corrolary of the results obtained in [12].

Remark 3. The $(L, p)$-bounded operator is defined, for example, in [12].

Suppose that $\mathcal{U}_{2}=\mathcal{F}_{2}=L_{2}(D)$. The equality $B_{2}=\delta \nabla^{2}:$ def $B_{2} \rightarrow \mathcal{F}_{2}$ defines the linear closed and densely defined operator $B_{2}$, dom $B_{2}=W_{2}^{2}(D) \cap \stackrel{\circ}{W_{2}^{1}}(D)$. Let $A_{2} \equiv I$.

Theorem 5. The operator $B_{2}$ is strongly $A_{2}$-sectorial.

Proof. The statement of the theorem follows from the sectoriality of the operator $B_{2}[14]$.

Let $\mathcal{U}=\mathcal{U}_{1} \times \mathcal{U}_{2}, \mathcal{F}=\mathcal{F}_{1} \times \mathcal{F}_{2}$.

The vector $u$ of the space $\mathcal{U}$ has the form $u=\operatorname{col}\left(u_{\sigma}, u_{\pi}, u_{p}, w_{1}, \ldots, w_{K}, u_{b}\right)$, where $\operatorname{col}\left(u_{\sigma}, u_{\pi}, u_{p}, w_{1}, \ldots, w_{K}\right) \in \mathcal{U}_{1}$, and $u_{b} \in \mathcal{U}_{2}, u_{b}=\left(b_{\sigma}, b_{\pi}\right), b_{\sigma} \in \mathbf{H}_{\sigma}^{2}, b_{\pi} \in \mathbf{H}_{\pi}^{2}$. The vector $f \in \mathcal{F}$ has the similar form. Define the operators $L$ and $M$ by the equalities $L=A_{1} \otimes A_{2}$ and $M=B_{1} \otimes B_{2}$. The operator $L$ belongs to $\mathcal{L}(\mathcal{U} ; \mathcal{F})$, and the operator $M: \operatorname{dom} M \rightarrow \mathcal{F}$ is linear, closed and densely defined, $\operatorname{dom} M=\mathcal{U}_{1} \times \operatorname{dom} B_{2}$. 
Theorem 6. Let $\varkappa^{-1} \notin \sigma(A)$, then the operator $M$ is strongly $(L, 1)$-sectorial.

Proof. By virtue of Theorem 4 and the results of Paragraph 3.1. [12], the operator $B_{1}$ is strongly $\left(A_{1}, 1\right)$-sectorial. Therefore, taking into account Theorems 3 and 5 , we obtain that the statement of the theorem is true.

Let us construct the nonlinear operator $F$. Represent the operator as

where

$$
F=F_{1} \otimes F_{2},
$$

$$
\begin{gathered}
F_{1}=F_{1}\left(u_{\sigma}, u_{\pi}, b\right)=\operatorname{col}\left(-\Sigma\left(\left(\left(u_{\sigma}+u_{\pi}\right) \cdot \nabla\right)\left(u_{\sigma}+u_{\pi}\right)-2 \Omega \times\left(u_{\sigma}+u_{\pi}\right)+(\nabla \times b) \times b+f^{1}\right),\right. \\
-\Pi\left(\left(\left(u_{\sigma}+u_{\pi}\right) \cdot \nabla\right)\left(u_{\sigma}+u_{\pi}\right)-2 \Omega \times\left(u_{\sigma}+u_{\pi}\right)+(\nabla \times b) \times b+f^{1}\right), \underbrace{0, \ldots, 0}_{K+1}), \\
F_{2}=F_{2}\left(u_{\sigma}, u_{\pi}, b\right)=\nabla \times\left(\left(u_{\sigma}+u_{\pi}\right) \times b\right)+f^{2} .
\end{gathered}
$$

In our case, $\mathcal{U}_{M}=\mathcal{U}_{1} \times \operatorname{dom} B_{2}$, since the operator $B_{1}$ is continuous.

Theorem 7. The operator $F$ belongs to $\mathcal{C}^{\infty}\left(\mathcal{U}_{M} ; \mathcal{F}\right)$.

Proof. The statement of the theorem follows from the fact that for any $u \in \mathcal{U}_{M}$ the operator $F_{u}^{\prime}$ belongs to $\mathcal{L}\left(\mathcal{U}_{M} ; \mathcal{F}\right)$, the second Frechet derivative $F^{\prime \prime}{ }_{u}$ of the operator $F$ is the continuous bilinear operator that belongs to $\mathcal{U}_{M} \times \mathcal{U}_{M}$ in $\mathcal{F}$, and $F_{u}^{\prime \prime \prime} \equiv O$ (similarly to $[12])$.

Therefore, we have reduced (1), (2) to (3), (4), and we can consider these two problems to be equivalent. Let us verify the conditions of Theorems 1 and 2 .

\section{Theorem on Existence and Uniqueness of Solution}

By virtue of Theorem 6 and the results of Paragraph 3.1. [12], there exists the analytic semigroup $\left\{U^{t}: t \in \mathbb{R}_{+}\right\}$of the resolving operators of equation (6). In this case, $U^{t}$ is naturally represented as $U^{t}=V^{t} \times W^{t}$, where $V^{t}\left(W^{t}\right)$ is the restriction of the operator $U^{t}$ on $\mathcal{U}_{1}\left(\mathcal{U}_{2}\right)$. Since $B_{2}$ is sectorial, then $W^{t}=\exp \left(t B_{2}\right)$, and, therefore, the kernel of this semigroup is $\mathcal{W}^{\circ}=\{0\}$, and the image of this semigroup is $\mathcal{W}^{1}=\mathcal{U}_{2}$.

Consider the semigroup $\left\{V^{t}: t \in \mathbb{R}_{+}\right\}$. By virtue of Theorems 4 and 6 and results of Paragraph 3.1. [12], this semigroup is extended to the group $\left\{V^{t}: t \in \mathbb{R}\right\}$. The kernel of the semigroup is $\mathcal{V}^{0}=\mathcal{U}_{1}^{00} \oplus \mathcal{U}_{1}^{01}$, where $\mathcal{U}_{1}^{00}=\{0\} \times\{0\} \times \mathbf{H}_{p} \times\{0\} \times \ldots \times\{0\}\left(=\operatorname{ker} A_{1}\right.$ due to Theorem 5), and $\mathcal{U}_{1}^{01}=\Sigma A_{\varkappa}^{-1} A_{\varkappa \pi}^{-1}\left[\mathbf{H}_{\pi}^{2}\right] \times \mathbf{H}_{\pi}^{2} \times \underbrace{\{0\} \times \ldots \times\{0\}}_{K+1}$. Here $A_{\varkappa}=I-\varkappa A$, $A_{\varkappa \pi}$ is the restriction of the operator $\Pi A_{\varkappa}^{-1}$ on $\mathbf{H}_{\pi}$. It is known that if $\varkappa^{-1} \notin \sigma(A) \cup \sigma\left(A_{\sigma}\right)$, then the operator $A_{\varkappa \pi}: \mathbf{H}_{\pi} \rightarrow \mathbf{H}_{\pi}^{2}$ is topological linear isomorphism [12]. Denote by $\mathcal{U}_{1}^{1}$ the image of $\mathcal{V}^{1}$. Then, since the operator $B_{1}$ is strongly $\left(A_{1}, 1\right)$-sectorial, then the space $\mathcal{U}_{1}$ decomposes into the direct sum of the subspaces $\mathcal{U}_{1}=\mathcal{U}_{1}^{00} \oplus \mathcal{U}_{1}^{01} \oplus \mathcal{U}_{1}^{1}$.

Construct the operator $R$ (see (5), (6)). In our case, $R=B_{10}^{-1} A_{10} \in \mathcal{L}\left(\mathcal{U}_{1}^{00} \oplus \mathcal{U}_{1}^{01}\right)$, where $A_{10}\left(B_{10}\right)$ is the restriction of the operator $A_{1}\left(B_{1}\right)$ on $\mathcal{U}_{1}^{00} \oplus \mathcal{U}_{1}^{01}$. Note that the operator $B_{10}^{-1}$ exists due to Theorem 6 and the corresponding results obtained in [12]. By construction, $\operatorname{ker} R=\mathcal{U}_{1}^{00}$, and the paper [15] shows that $\operatorname{im} R=\mathcal{U}_{1}^{01}$. Therefore, the operator $R$ is bi-splitting. Denote by $P_{R}$ the projector of the space $\mathcal{U}_{1}^{00} \oplus \mathcal{U}_{1}^{01}$ on $\mathcal{U}_{1}^{00}$ along $\mathcal{U}_{1}^{01}$. Taking into account the structure of the space $\mathcal{U}_{M}$, we obtain that the projector $P_{R}$ belongs to $\mathcal{L}\left(\mathcal{U}_{M}^{0}\right)$, where $\mathcal{U}_{M}^{0}=\mathcal{U}_{M} \cap\left(\mathcal{U}_{1}^{00} \oplus \mathcal{U}_{1}^{01}\right)\left(\equiv \mathcal{U}_{1}^{00} \oplus \mathcal{U}_{1}^{01}\right)$. Therefore, the following lemma is valid. 
Lemma 1. Suppose that $\varkappa^{-1} \notin \sigma(A) \cup \sigma\left(A_{\sigma}\right)$. Then the operator $R$ is bi-splitting, and $P_{R} \in \mathcal{L}\left(\mathcal{U}_{M}^{0}\right)$.

Consider the projectors

$$
P_{k}=\operatorname{diag}\left[\hat{P}_{k}, 0\right], \quad Q_{k}=\operatorname{diag}\left[\hat{Q}_{k}, 0\right], \quad k=0,1,
$$

see [12] for a detailed description of these projectors. Taking into account the results of [12] and the fact that the kernel $\mathcal{W}^{0}=\{0\}$, we obtain that $I-P=\left(P_{0}+P_{1}\right) \times O, \quad Q=$ $\left(I-Q_{0}-Q_{1}\right) \times I, \quad P: \mathcal{U} \rightarrow \mathcal{U}^{1}, \quad Q: \mathcal{F} \rightarrow \mathcal{F}^{1}$.) Then, apply the projector $I P$ to equation (4) in our situation and obtain the equations

$$
\begin{gathered}
\Pi\left(\nu A\left(u_{\sigma}+u_{\pi}\right)-\left(\left(u_{\sigma}+u_{\pi}\right) \cdot \nabla\right)\left(u_{\sigma}+u_{\pi}\right)+\sum_{l=1}^{K} \beta_{l} \nabla^{2} w_{l}-u_{p}-2 \Omega \times\left(u_{\sigma}+u_{\pi}\right)+\right. \\
\left.(\nabla \times b) \times b+f^{1}(t)\right)=0, \quad B u_{\pi}=0, \quad B b_{\pi}=0 .
\end{gathered}
$$

Hence, by virtue of Theorem 1 and the properties of the operator $B$, we obtain the necessary condition for existence of the quasi-stationary trajectory $u_{\pi} \equiv 0, b_{\pi} \equiv 0$, i.e. all solutions to problem (2), (13) (if they exist) necessarily belong to the plane $\mathcal{B}=\{u \in$ $\left.\mathcal{U}_{M}: u_{\pi}=0, b_{\pi}=0\right\}$.

Since $\Pi u_{p}=u_{p}$, we obtain relation (9) from the first equation of (14), i.e. in our case,

$$
u_{p}=\Pi\left(\nu A u_{\sigma}-\left(u_{\sigma} \cdot \nabla\right) u_{\sigma}+\sum_{l=1}^{K} \beta_{l} \nabla^{2} w_{l}-2 \Omega \times u_{\sigma}+\left(\nabla \times b_{\sigma}\right) \times b_{\sigma}+f^{1}(t)\right) .
$$

Lemma 2. Under the conditions of Lemma 1, any solution to problem (1), (2) belongs to the set

$$
\begin{aligned}
\mathfrak{M}=\left\{u \in \mathcal{U}_{M}: u_{\pi}=0, b_{\pi}=\right. & 0, u_{p}=\Pi\left(\nu A_{\sigma}-\left(u_{\sigma} \cdot \nabla\right) u_{\sigma}+\sum_{l=1}^{K} \beta_{l} \nabla^{2} w_{l}-2 \Omega \times u_{\sigma}+\right. \\
& \left.\left.+\left(\nabla \times b_{\sigma}\right) \times b_{\sigma}\right)+f^{1}(t)\right\} .
\end{aligned}
$$

Remark 4. Relation (15) gives condition $\mathrm{A}_{2}$ ) of Theorem 2 for any point $u_{0}^{0} \in \mathcal{U}_{M}^{00}(\equiv$ $\left.\mathcal{U}_{1}^{00} \times\{0\}\right)$. Therefore, similarly to [12], we obtain that the set $\mathfrak{M}$ is a simple Banach manifold that is $\mathcal{C}^{\infty}$-diffeomorphic to the subspace $\mathcal{U}_{1}^{1} \times \mathcal{U}_{2}$, and can be the extended phase space of problem (1), (2) ((13), (2)).

Let us verify conditions (11), (12). Construct the space $\mathcal{U}_{\alpha}=\mathcal{U}_{1} \times \stackrel{\circ}{W}{ }_{2}^{1}(D)$. Obviously, this space is the interpolation space for the pair $\left[\mathcal{U}, \mathcal{U}_{M}\right]_{\alpha}$, and $\alpha=1 / 2$. As noted above, the semigroup $\left\{U^{t}: t \in \mathbb{R}_{+}\right\}$is extended to the group $\left\{V_{1}^{t}: t \in \mathbb{R}\right\}$ on $\mathcal{U}_{1}^{1}$, where $V_{1}^{t}$ is the restriction of the operator $V^{t}$ on $\mathcal{U}_{1}^{1}$. Since $\mathcal{U}_{M}^{1}=\mathcal{U}_{M} \cap \mathcal{U}_{1}^{1}$ by construction, the operator $B_{1}$ is continuous by virtue of Theorem 4 , and the semigroup $\left\{U^{t}: t \in \mathbb{R}_{+}\right\}$is uniformly bounded, we obtain the inequality

$$
\int_{0}^{\tau}\left\|V_{1}^{t}\right\|_{\mathcal{L}\left(\mathcal{U}_{1}^{1} ; \mathcal{U}_{M}^{1}\right)} d t \leq \mathrm{const} \times\left\|B_{1}\right\|_{\mathcal{L}\left(\mathcal{U}_{1} ; \mathcal{F}_{1}\right)} \int_{0}^{\tau}\left\|V_{1}^{t}\right\|_{\mathcal{L}\left(\mathcal{U}_{1}^{1}\right)} d t<\infty, \quad \tau \in \mathbb{R}_{+} .
$$

According to Sobolev's inequality [12], the semigroup $\left\{W^{t}: t \in \overline{\mathbb{R}}_{+}\right\}$satisfies the estimate

$$
\int_{0}^{\tau}\left\|W^{t}\right\|_{\mathcal{L}\left(\operatorname{dom} B_{2} ; \stackrel{\circ}{2}_{2}^{1}(D)\right)} d t<\infty .
$$

Suppose that $\mathcal{U}_{\alpha}^{1}=\mathcal{U}_{\alpha} \cap \mathcal{U}^{1}$, where $\mathcal{U}^{1}=\mathcal{U}_{1}^{1} \times \mathcal{U}_{2}$. Then inequalities (16) and (17) give the following lemma.

Lemma 3. Under the conditions of Lemma 1, relation (11) takes place. 
Taking into account condition (12), we obtain the operator $H$ as follows. The operator $H$ is naturally represented as $H=H_{1} \otimes H_{2}$, where $H_{1}=A_{11}^{-1}\left(I-Q_{0}-Q_{1}\right) F_{1}$, and $H_{2} \equiv F_{2}$ ( $A_{11}$ is the restriction of the operator $A_{1}$ on $\mathcal{U}_{1}^{1}$ ). For the operator $H$, there is the statement that is similar to Theorem 7 for the operator $F$, i.e. $H \in \mathcal{C}^{\infty}\left(\mathcal{U}_{M}^{1} ; \mathcal{U}_{\alpha}^{1}\right)$, where $\mathcal{U}_{\alpha}^{1}=\mathcal{U}_{\alpha} \cap \mathcal{U}^{1}$.

Therefore, all the conditions of Theorem 2 are satisfied. Therefore, the following statement is valid.

Theorem 8. Suppose that $\varkappa^{-1} \notin \sigma(A) \cup \sigma\left(A_{\sigma}\right)$. Then for any $u_{0}$ such that $u_{0} \in \mathfrak{M}$, and some $T \in \mathbb{R}_{+}$, there exists the unique solution $u=\left(u_{\sigma}, 0, u_{p}, u_{b}\right)$ to problem (1), (2), which is a quasi-stationary trajectory, and $u(t) \in \mathfrak{M}$ for all $t \in(0, T)$.

Acknowledgements. The authors express their gratitude to Professor G.A. Sviridyuk for his attention and constructive criticism. The work was supported by the Government of the Russian Federation (act 211, contract no. 02.A03.21.0011).

\section{References}

1. Oskolkov A.P. Initial-Boundary Value Problems for the Equations of the Motion of the Kelvin-Voight and Oldroyd Fluids. Proceedings of the Steklov Institute of Mathematics (Trudy Matematicheskogo instituta imeni V.A. Steklova), 1988, no. 179, pp. 126-164. (in Russian)

2. Hide R. On Planetary Atmospheres and Interiors. Providence, American Mathematical Society, 1971.

3. Sukacheva T.G., Kondyukov A.O. Phase Space of a Model of Magnetohydrodynamics. Differential Equations, 2015, vol. 51, no. 4, pp. 502-509. DOI: 10.1134/S0012266115040072

4. Kadchenko S.I., Kondyukov A.O. Numerical Study of a Flow of Viscoelastic Fluid of KelvinVoigt Having Zero Order in a Magnetic Field. Journal of Computational and Engineering Mathematics, 2016, vol. 3, no. 2, pp. 40-47. DOI: 10.14529/jcem1602005

5. Sukacheva T.G., Kondyukov A.O. Phase Space of a Model of Magnetohydrodynamics of Nonzero Order. Differential Equations, 2017, vol. 53, no. 8, pp. 1054-1061. DOI: $10.1134 / \mathrm{S} 0012266117080109$

6. Kondyukov A.O. Generalized Model of Incompressible Viscoelastic Fluid in the Earth's Magnetic Field. Bulletin of the South Ural State University. Series: Mathematical. Mechanics. Physics, 2016, vol. 8, no. 3, pp. 13-21. (in Russian)

7. Kondyukov A.O., Sukacheva T.G., Kadchenko S.I., Ryazanova L.S. Computational Experiment for a Class of Mathematical Models of Magnetohydrodynamics. Bulletin of the South Ural State University. Series: Mathematical Modelling, Programming and Computer Software, 2017, vol. 10, no. 1, pp. 149-155. DOI: 10.14529/mmp170110

8. Sviridyuk G.A., Sukacheva T.G. [Phase Spaces of a Class of Operator Equations]. Differential Equations, 1990, vol. 26, no. 2, pp. 250-258. (in Russian)

9. Sviridyuk G.A., Sukacheva T.G. [The Cauchy Problem for a Class of Semilinear Equations of Sobolev Type]. Sibirskii matematicheskii zhurnal, 1990, vol. 31, no. 5, pp. 109-119. (in Russian)

10. Sviridyuk G.A. On the General Theory of Operator Semigroups. Russian Mathematical Surveys, 1994, vol. 49, no. 4, pp. 45-74. DOI: 10.1070/RM1994v049n04ABEH002390

11. Sviridyuk G.A., Fedorov V.E. Linear Sobolev Type Equations and Degenerate Semigroups of Operators. Utrecht, Boston, Köln, Tokyo, VSP, 2003. 
12. Matveeva O.P., Sukacheva T.G. Matematicheskie modeli vyazkouprugikh neszhimaemykh zhidkostey nenulevogo poryadka [The Mathematical Models of a Viscoelastic Incompressible Fluid of Nonzero Order]. Chelyabinsk, Publishing Center of South Ural State University, 2014. (in Russian)

13. Sviridyuk G.A. Quasistationary Trajectories of Semilinear Dynamical Equations of Sobolev Type. Russian Academy of Sciences. Izvestiya Mathematics, 1993, vol. 57, no. 3, pp. 192-207. (in Russian)

14. Henry D. Geometric Theory of Semilinear Parabolic Equations. Series: Lecture Notes in Mathematics, Vol. 840. Berlin, Springer, 1981.

15. Sviridyuk G.A. On a Model of Weakly Viscoelastic Fluid. Russian Mathematics (Izvestiya VUZ. Matematika), 1994, vol. 38, no. 1, pp. 59-68. (in Russian)

Received April 21, 2019

\title{
НЕСТАЦИОНАРНАЯ МОДЕЛЬ НЕСЖИМАЕМОЙ ВЯЗКОУПРУГОЙ ЖИДКОСТИ КЕЛЬВИНА - ФОЙГТА НЕНУЛЕВОГО ПОРЯДКА В МАГНИТНОМ ПОЛЕ ЗЕМЛИ
}

\author{
А.О. Кондюков ${ }^{1}$, Т.Г. Сукачева ${ }^{1,2}$ \\ ${ }^{1}$ Новгородский государственный университет им. Ярослава Мудрого, \\ г. Великий Новгород, Российская Федерация \\ ${ }^{2}$ Южно-Уральский государственный университет, г. Челябинск, \\ Российская Федерация
}

В работе исследуется задача Коши - Дирихле для системы уравнений Осколкова ненулевого порядка. Рассматриваемая математическая модель описывает течение несжимаемой вязкоупругой жидкости Кельвина - Фойгта в магнитном поле Земли. При этом учитывается, что на жидкость оказывают влияние различные внешние воздействия, зависящие как от координаты точки в пространстве, так и от времени. В первой части работы излагаются известные результаты, полученные авторами ранее, из теории разрешимости задачи Коши для полулинейных неавтономных уравнений соболевского типа. Во второй части проводится редукция рассматриваемой математической модели к указанной абстрактной задаче Коши. В третьей части доказывается основной результат - теорема существования и единственности решения. Находятся условия существования квазистационарных полутраекторий, а также описывается расширенное фазовое пространство исследуемой модели. Представленные в статье исследования обобщают результаты авторов для системы Осколкова, моделирующей движение вязкоупругой несжимаемой жидкости Кельвина - Фойгта нулевого порядка в магнитном поле Земли.

Ключевые слова: магнитогидродинамика; уравнения соболевского типа; расширенное фазовое пространство; несжимаемая вязкоупругая жидкость.

\section{Литература}

1. Осколков, А.П. Начально-краевые задачи для уравнений движения жидкостей Кельвина - Фойгта и Олдройта / А.П. Осколков // Труды математического института АН СССР. 1988. - T. 179. - C. $126-164$. 
2. Hide, R. On Planetary Atmospheres and Interiors / R. Hide. - Providence: American Mathematical Society, 1971.

3. Сукачева, Т.Г. Фазовое пространство одной модели магнитогидродинамики / Т.Г. Сукачева, А.О. Кондюков // Дифференциальные уравнения. - 2015. - Т. 51, № 4. - С. 495-501.

4. Kadchenko, S.I. Numerical Study of a Flow of Viscoelastic Fluid of Kelvin - Voigt Having Zero Order in a Magnetic Field / S.I. Kadchenko, A.O. Kondyukov // Journal of Computational and Engineering Mathematics. - 2016. - V. 3, № 2. - P. 40-47.

5. Сукачева, Т.Г. Фазовое пространство модели магнитогидродинамики ненулевого порядка / Т.Г. Сукачева, А.О. Кондюков // Дифференциальные уравнения. - 2017. - Т. 53, № 8. - C. 1083-1090.

6. Кондюков, А.О. Обобщенная модель несжимаемой вязкоупругой жидкости в магнитном поле Земли / А.О. Кондюков // Вестник ЮУрГУ. Серия: Математика. Механика. Физика. - 2016. - Т. 8, № 3. - С. 13-21.

7. Kondyukov, A.O. Computational Experiment for a Class of Mathematical Models of Magnetohydrodynamics / A.O. Kondyukov, T.G. Sukacheva, S.I. Kadchenko, L.S. Ryazanova // Вестник ЮУрГУ. Серия: Математическое моделирование и программирование. 2017. - T. 10, № 1. - C. 149-155.

8. Свиридюк, Г.А. Фазовые пространства одного класса операторных уравнений / Г.А. Свиридюк, Т.Г. Сукачева / Дифференциальные уравнения. - 1990. - Т. 26, № 2. C. $250-258$.

9. Свиридюк, Г.А. Задача Коши для одного класса полулинейных уравнений типа Соболева / Г.А. Свиридюк, Т.Г. Сукачева / Сибирский математический журнал. - 1990. - Т. 31, № 5. - C. 109-119.

10. Свиридюк, Г.А. К общей теории полугрупп операторов / Г.А. Свиридюк // Успехи математических наук. - 1994. - Т. 49, № 4. - С. 47-74.

11. Sviridyuk, G.A. Linear Sobolev Type Equations and Degenerate Semigroups of Operators / G.A. Sviridyuk, V.E. Fedorov. - Utrecht; Boston; Köln; Tokyo: VSP, 2003.

12. Матвеева, О.П. Математические модели вязкоупругих несжимаемых жидкосей ненулевого порядка / О.П. Матвеева, Т.Г. Сукачева. - Челябинск: Издательский центр ЮУрГУ, 2014.

13. Свиридюк, Г.А. Квазистационарные траектории полулинейных динамических уравнений типа Соболева / Г.А. Свиридюк // Известия вузов. Математика. - 1993. - Т. 57, № 3. - С. 192-207.

14. Хенри, Д. Геомерическая теория полулинейных параболических уравнений / Д. Хенри. М.: Мир, 1985.

15. Свиридюк, Г.А. Об одной модели слабосжимаемой вязкоупругой жидкости / Г.А. Свиридюк // Известия вузов. Математика. - 1994. - № 1. - С. 62-70.

Алексей Олегович Кондюков, кандидат физико-математических наук, старший преподаватель, кафедра алгебры и геометрии, Новгородский государственный университет им. Ярослава Мудрого (г. Великий Новгород, Российская Федерация), k.a.o_leksey999@mail.ru.

Тамара Геннадьевна Сукачева, доктор физико-математических наук, професcop, кафедра алгебры и геометрии, Новгородский государственный университет им. Ярослава Мудрого (г. Великий Новгород, Российская Федерация); научноисследовательская лаборатория «Неклассические уравнения математической физики», Южно-Уральский государственный университет (г. Челябинск, Российская Федерация), tamara.sukacheva@novsu.ru.

Поступила в редакиию 21 апреля 2019 г.

и программирование» (Вестник ЮУрГУ ММП). 2019. Т. 12, № 3. С. 42-51 